\title{
Integrated Methodology for Co-designing and Co-creating for Sustainable Sanitation Project
}

\author{
Edward Appiah $^{1 *}$ Patrick Gyamfi ${ }^{1}$ Ralitsa Dian Debrah ${ }^{1}$ \\ 1. Faculty of Art, Kwame Nkrumah University of Science \& Technology, Kumasi, Ghana \\ * E-mail of the corresponding author: eddappiah@gmail.com
}

\begin{abstract}
The study explored the framework for an integrated methodology for co-designing and co-creation (collaboratively), in prototyping a design system for tackling sanitation issues within a section of a community in Ghana. The aim was to test an integrated approach in exploring design-thinking approaches that stimulate, and support sustainable environmental sanitation, through behaviour changes. With the framework as our methodological approach to generate a sustainably clean environment with end users, we sought to explore the benefits of stakeholders' voices in decision-making in sanitation planning; and ascertain their contributions to improving their environment as a result of behaviour change. The results indicate that integrated methodologies are flexible and useful when prototyping with design systems especially with the stakeholders (co-designers) in collaborative (design intervention) approach. Stakeholders' voices when heard, in decision-making, do not just encourage sanitation planning on their streets and environment, but also helped boost the self-efficacy of managing their sanitation challenges.
\end{abstract}

Keywords: Integrated Methodologies, FraIM, Sustainable Sanitation, Environmental Sanitation, Design thinking

DOI: $10.7176 / \mathrm{ADS} / 83-11$

Publication date:July $31^{\text {st }} 2020$

\section{Introduction}

Doing research in design has been fraught with many controversies in terms of methodologies. The rejection of the traditional dichotomies of qualitative and quantitative methods, gave rise to mixed methods (Tashakkori and Creswell 2007). Within the creative fratenity, the issue of practice-led and practice-based research has also come to the fore (Sullivan 2009). Sullivan (2009) has proposed arts-based research within educational contexts. According to him, "research practices that are inherently discipline-centred in the arts and humanities whereby practice-led research in the arts is considered an area of inquiry that is important in its own right" (Sullivan 2009). Researchers have advocated for collaborative research (co-designing and co-creation) in design, especially with stakeholders input. If "(design) is concerned with how things ought to be - how they ought to be in order to attain goals and to function"(Manzini 2015), then we need to look at multiplicity of methodologies that will help attain the required goals. And it is in this vein that this study adopted the framework for an integrated methodology (FraIM), in prototyping design oriented activity on sustainable sanitation challenges.

The study employed the Framework for an integrated methodology (FraIM), as proposed by Plowright (2011), not in its basic form but in its integrated aspect. The framework looks at how to approach research using an integrated methodology, based on a pragmatic philosophy underpinned by an empirical epistemology. It provides an opportunity to develop an understanding of how to use an integrated methodology that meets the needs of a researcher who wants to challenge the traditional paradigmatic view of research. The basic model of the FraIM proposes a research from a research question, cases, methods, data, data analysis, evidence, claims and conclusions (Fig. 1).

From its integrated structure, the research focused on the question: "to what extent can community engagement help to attain a sustainable environmental sanitation in a deprived environment?" The aim was to test an integrated approach in in employing design-thinking approach with other methods that stimulate and support sustainable environmental sanitation in that community, and to attain a sustainable environmental sanitation, through behaviour changes. 
Fig. 1: The Basis structure of the FraIM

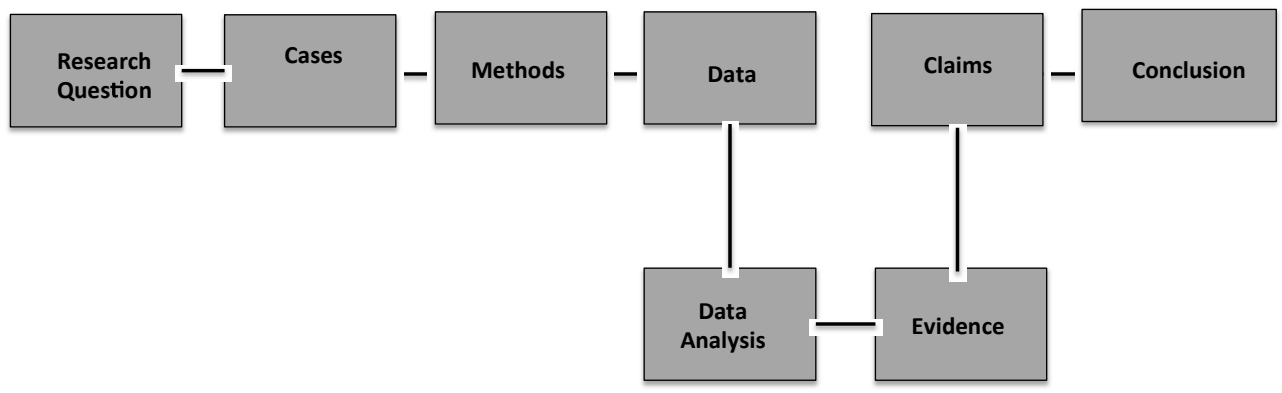

\section{Case}

In Ghana, efforts are being made by governments through Local Government and Rural Development Ministry, non-governmental organizations among others to implement interventions to persuade and engage citizens to adapt the proper attitude to environmental cleanliness. Communication tools (posters, billboards, television, radio and social networks), as well as some innovative programmes such as "ECOSAN", "WASH" and "CLTS" have been used for encouraging proper attitude to sanitation. Such efforts have achieved some level of success in some communities in the country.

However, the task seems to be confronted with reoccurring difficulties and hence, appear to be ineffective especially in some underserved areas such as the Zongo communities in Ghana. Research indicate irresponsible human activity: inappropriate control of livestock, poorly maintained toilet facilities; illicit building extensions; poorly preserved drainage system (either collapsed or choked with refuse); has been the bane of some deprived communities in Ghana (Adubofour, Obiri-Danso, and Quansah 2013). They also mentioned congested accommodation; unhealthy environs and the generation of large volumes of solid waste, as other bane for such communities.

Though government agencies have largely depended on the media for public sensitization to help minimise the current circumstances, studies show that the heavy flow of media messages produced have practically failed to capture the attention of most receivers or create any profound change (Atkin 2001). Again, assumption by planners that when people are well informed, they avoid unsanitary practices and embrace hygienic living is not always true (Van Wijk, Murre, and Esrey 1995). To add to that, studies reveals that in Ghana, the media have all it takes to help change attitudes to the environment but they often focus on issues of little value to national development (Asante 2012).

Managers of the city have tried maintaining a clean environment but the task seems to be daunting and is challenged by creating for itself a picture of unsustainability. One of the main reasons for this seemingly challenging situation stems from the attitude of the citizens, whose behaviour and tendencies seem to be difficult to change. Acheampong (2010) estimates that the driving force for environmental uncleanliness in the deprived communities is attitudinal in origin. This study sought to test a social innovation intervention with the inhabitants of Moshie Zongo, a less deprived community in Kumasi, for attitudinal change. This was through a design approach using an integrated method, which in turn could be replicated in other communities in Ghana. The aim was to explore how a design approach can stimulate and support sustainable environmental sanitation by changing the attitude of inhabitants-through the ambit of design thinking. The was guided by the following research questions:

1. How do stakeholders perceive the conditions of their environment using participatory design-thinking approach?

2. What contributions can stakeholders - landlords, tenants, and residents - make to enhance the environment as far as sanitation and environmental sustainability is concerned?

\section{Methodologies}

In establishing the case as a data source for the study, the researchers were mindful of the appropriateness and the population involved in such a community. Moshie Zongo, though a deprived area, is also a famous community. It 
is a Muslim community and was chosen as the study settlement owing to the common assessment that the community was one of the worst parts of the city and prone to diseases, going by records from the Health Education Unit (Saywell and Hunt 1999). This case study area involved two selected streets of approximately 40 houses on each street. This was based on the prescription of Plowright (2011) that "cases need not necessary be individuals or organisations. They can be objects such as desks in a school, bus shelters or notice boards in a building". The choice of the streets encompassed a small sample size of landlords, tenants and residents that helped the researchers to make deductions that facilitated the explanatory nature of the study. The sample limited to a couple of residents who live in different houses or work around and along the two specific streets. They also comprised landlords or landladies, tenants and food vendors or shopkeepers (residents or non-residents) who were usually around, on the streets.

With the case carefully formulated, the researchers decided to employ appropriate methods that sought to make available enough data. Other factors that were considered included logistical issues, and degree of control, as prescribed by the FraIM. The choice of multi methods, including ethnographic approach on the field (used to study other cultures) were considered to be significant in that context (Hunn, Fox, and Hunn 1998). Brewer (2000) describes ethnography as "the study of people in naturally occurring settings or fields by means of methods which capture their social meanings and ordinary happenings, involving the researcher partaking directly in the setting, if not also the activities, in order to collect data in a systematic manner but without meaning being imposed on them externally." We therefore involved key figures within the community in respect of specific groups and cultures, to make available beneficial information on the community (Wiles \& Crow 2013). By ethnography, we were able to deeply understand the residents who happened to be the end-users of the design solution. It also helped us to remained committed to getting connected to residents consistently, contrary to a misconception of being hostile. This healthy relationship inspired the researchers throughout the study.

\subsection{Design Thinking as Intervention}

Activities were formulated for the implementation of the objectives to attain possible maintainable solutions to the sanitary issue. The researchers were mindful of design thinking as an intervention at this stage. Design thinking is a non-linear, iterative process which seeks to understand users, challenge assumptions, redefine problems and create innovative solutions to prototype and test. The method consists of 5 phases-Empathize, Define, Ideate, Prototype and Test and is most useful when one wants to tackle problems that are ill-defined or unknown (Fig 2).

Figure 2: Design thinking process (Interaction-design.org)

\section{Design Thinking: A 5-Stage Process}

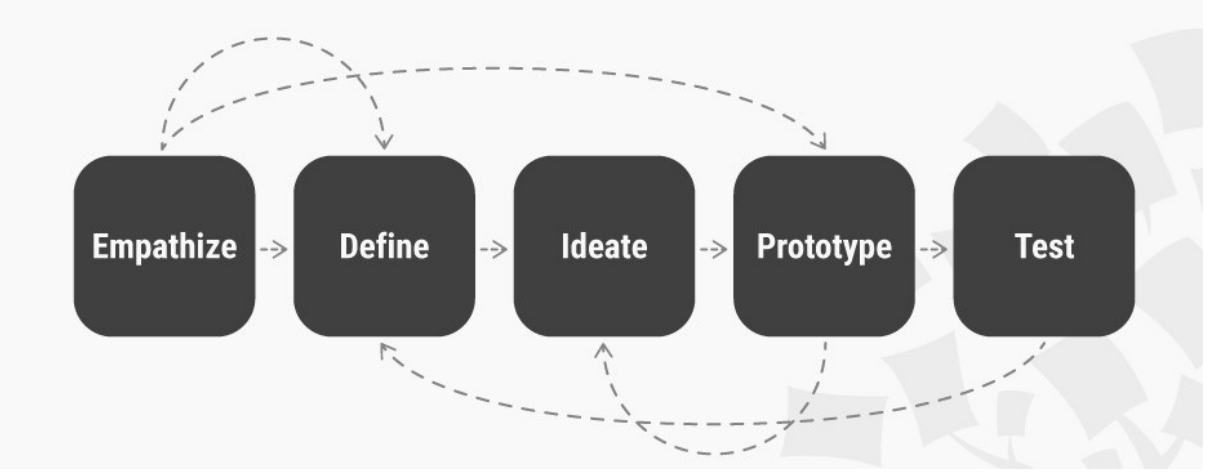

The main objective was to create the appropriate collaborative environment for establishing a framework for cleaning and maintaining a sustainable clean environment. This can be done through the integrated process of a repeated pattern of research or analysis and team workshops in each phase of the project (Lee, 2014). In Lee's (2014) framework, designers shared expertise from various individuals in their related fields during the pre-design phase; constructed and justified initial concepts and ideas during the design development phase; and disseminated the new knowledge during the documentation and presentation phase. Such new knowledge can be adopted for future practice, and can become new custom for achieving a sustainable clean environment.

The intervention code-named "5-Star Street Project" drew on the motivation of awarding each street with a "Star", which would be tagged to the Street's name after street residents fulfilled basic sanitation and environmental instructions. This is in line with United Nations Development Programme (UNDP) belief that such targets can 
only be attained through equipping individuals, households, and communities to take charge of their own development (Conant, 2005). In this context, 3-Star Street would imply such a street where residents and all users on that street - were more environmental and sanitation conscious than a 1-Star Street. It also meant a 3-Star Street is much superior in terms of all that would happen on the street to 1-Star or No-star Street. A 5-Star Street would seem to be above all standards, and hence, possess the ultimate superiority tag. Residents in this case would therefore have to consistently make conscious effort to maintain the status of their streets since there is a possibility of a 5-Star Street being downgraded. A sustainable design required environmental solutions with a sustainable future, environmental solutions sought within a complete and profound perspective on the relationship between dwellers and the environment beyond mere technical solutions (Lee, 2014).

\subsection{Pre-design Phase}

The plan for the pre-design phase for the study was hinged on the following cardinal factors:

i. Scheduling a series of participatory events involving residents, experts, cooperation partners, networks, employees of related agencies relating to waste management, and other interested parties. The outcome of these events, together with that of the focus groups resulted in the articulation of seven core values put together to be explored as part of the development process and ultimately to be incorporated into the 5-Star Street Project. These were:

1. The residents as Key Factor;

2. Lifelong Learning and Community;

3. Diversity, Cooperation, and Network;

4. Culture and Experiences;

5. Bridging Citizens, Technology, and Knowledge;

6. Flexible and Community but Professional Organization; and

7. Sustainable Icon for the community (Dalsgaard, 2012).

ii. Identification and exploration of the factors influencing residents in understanding the sanitation challenges, and the problems concerning providing adequate and appropriate tools for the maintenance of sustainable environmental sanitation. Three focus group discussions and interviews with landlords, tenants, and residents on a particular each of the two streets were carried out to achieve this goal.

iii. Conventional events for involving stakeholders, including public hearings, were held throughout the process. These events were typically open events announced to residents of the two streets in the community that featured the presentation of a specific aspect of the project (e.g., the idea development issues or accessibility issues), followed by open discussions. Participatory Design techniques were also used in more focused events, such as inspiration, and workshops. These workshops were collaborative design events in which professional designers and participants had knowledge of the design domain and combined sources of inspiration and interactive technologies to create design concepts.

iv. Based on the outcome of (i), a number of collaborative discussions were also carried out with the stakeholders and residents on each of the two streets to formulate objectives to improve the situation and to resolve identified challenges.

The researchers, the assemblyman, resource persons, technocrats and other stakeholders were assigned to specific activities for the design and action stage ahead of time.

\subsection{Focus Group Discussions and Interview as Methods}

The inclusion of focus group discussions with the participants had significant impact on the overall project through their answers to the ideas and contributions for the duration of the dialogue (Jenkins, 1998). This part of the study was in alignment with its objectives. Meetings were held on two occasions for the residents who made time to be part of the programme from both streets. The first author, who doubled as the moderator, created a warm and friendly environment for participants before hand. The introductory stage of the discussion was treated cautiously since it is believed that, "the first few minutes in focus group discussion is always critical" (Krueger, 2002). This was also to alley fears of misconception being entertained by the residents who might still be harbouring some sense of "insecurity."

The focus of the focus groups' discussions was to encourage residents as stakeholders, to bring out some of the challenges encouraging their insanitary practices. Kasper (2008) for instance believes that individuals or groups of people who turn their plans into results using design to initiate innovation within various societies with differing 
values can adopt design for social innovation. It is one of the most dynamic, extensive forces in the world today for those, using design to drive innovation, and who seeks to turn their good intentions into positive outcomes.

The focus groups were targeted to empathise with the residents to identify sanitation issues on both streets, and to seek their views on proper sanitation and on other matters relating to the objectives of the study. These focus groups and interviews revealed that, many residents, in pretence, shortly keep their surroundings tidy upon having a hint about the presence of sanitary inspectors. Deploying the services of the sanitary inspectors to curtail insanitary practices had remain unsustainable because when residents are caught unawares in a filthy environment, the culprits almost always apologise and beg for clemency. This however, never encouraged behaviour change and moreover, the current punitive system continually proves to be unreliable and unsustainable as far as solutions to insanitary practices are concerned. It is undoubted that co-designing remains useful to social innovation. Szebeko and Tan, (2010) state that social innovation "can be an influential and transformation managing tool, encouraging the collaboration of people within organisations and among local communities and also offers a foundation for citizens to become active in taking on more accountability in their own health and wellbeing and brings "intrinsic value" where "the act of participation is valuable in itself, quite apart from any value it may have in helping to achieve other good things"

Having agreed categorically that there was environmental sanitation challenges on their streets, it was deemed expedient to inquire and pinpoint topics for discussion to arrive at recommendable solutions as residents.

\subsection{Population}

For the choice for population, stratified random sampling was implemented since preferred and varied residents were used for both the focus group discussion and interviews. The sample was limited to a couple of residents who lived in different houses or work around and along the two specific streets. These respondents, as discussed earlier, comprised landlords/landladies, tenants and food vendors or shop keepers (residents or non-residents) who were usually around, on the streets, who ere also seen as stakeholders.

\subsubsection{Population}

Residents of two selected streets formed the sampling units in the design. First, the researcher with the aid of the assembly member (an opinion leader) of the community built a steady rapport with landlords or caretakers as well as residents on both streets. The names of such residents were compiled with their contacts for effective and consistent communication. These two streets were chosen owing to their virtual similarity in societal structure. It was also to enable equity and fairness in constant competition between the two streets as regards which one kept a cleaner environment. This competition stimulated residents of both streets making them desirous of attaining premium recognition as the cleanest street. More importantly, it was to discover and tap the communal and cultural resources of knowledge available in both settings.

Since participatory design research can be applied to sustainable design research, the underpinning issue of this study was to overcome the various problems encountered in developing and maintaining a system that will create an enhanced and sustained clean environment with the aid of conceptual design. The researchers carefully identified a variety of responses to policy and how professionals and non-professionals coped with the situations of environmental sanitation. Thus, views of the research participants, residents, landlords and designers were captured instead of official educational assumptions. The stakeholders' involvement required the inclusion of many people who, one way or the other needed to be educated through workshops or be sensitized by resource persons to have a clear understanding of the project.

\subsection{Data for analysis}

Residents of two selected streets formed the sampling units in the design. First, the researcher with the aid of the assembly member (an opinion leader) of the community built a steady rapport with landlords or caretakers as well as residents on both streets. The names of such residents were compiled with their contacts for effective and consistent communication. These two streets were chosen owing to their virtual similarity in societal structure. It was also to enable equity and fairness in constant competition between the two streets as regards which one kept a cleaner environment. This competition stimulated residents of both streets making them desirous of attaining premium recognition as the cleanest street. More importantly, it was to discover and tap the communal and cultural resources of knowledge available in both settings.

Since participatory design research can be applied to sustainable design research, the underpinning issue of this study was to overcome the various problems encountered in developing and maintaining a system that will create an enhanced and sustained clean environment with the aid of conceptual design. The researchers carefully identified a variety of responses to policy and how professionals and non-professionals coped with the situations 
of environmental sanitation. Thus, views of the research participants, residents, landlords and designers were captured instead of official educational assumptions. The stakeholders' involvement required the inclusion of many people who, one way or the other needed to be educated through workshops or be sensitized by resource persons to have a clear understanding of the project.

\section{Evidences}

\subsection{Sensitization Programme}

Attaining maintainable behavioural change towards environmental sanitation among residents of the two streets remained the ultimate goal throughout this study. The need for creating awareness was therefore deemed an integral step in this study. Researchers are of the view that people mostly adopt a subjective stand in situations they have predictable mental biases that affect how they perceive situations and make decisions (Weinreich 2011). It was hence necessary to correct a few misconceptions about sanitation that were the obstacle to improved sanitation among residents. The sensitisation programme was the initial cooperative dialogue for the study. It involved residents of the target community, resource persons and technocrats. This dialogue was conducted for clearer and profound understanding of the study to foster involvement among the stakeholders. This goal was attained in that, residents demonstrated the willingness to cooperate with other researchers and thus became "co-researchers". Such interactions also afforded the opportunity for residents, as stakeholders, to ask questions that baffled their minds about the study in particular, and about sustainable environmental sanitation in general.

\subsection{Ethnographic Activities - Outcome from end-users}

The ethnographic approach precipitated a deeper understanding of the cultural and social settings in the community. This period also revealed an in-depth study to ascertain from existing literature, what the generic issues were on environmental sanitation at the "Zongo" societies. Alexander, (2008) asserts that, environmental sanitation is not only about hygiene and disease; but also about dignity; and everyone in the world has the right to have it. Arguably, it did not take long to notice the extreme deprivation and denial of the right to clean environment during the ethnographic tour. The situation in most parts of the community was observed to be a true reflection of the findings in research by Williamson (2014) which revealed that 'severe cases to that effect are noted among underprivileged nations in the world such as Ghana, where reckless disposal of solid waste into gutters and water bodies by some citizens consequently impede drainage system and trigger flood cases which destroy human life in diverse ways'.

Engagement with the inhabitants over ten months, moreover, cautioned the researchers to be circumspect with people who appear to be deviant in a society. Rather than indulge in ruthless criticism, it was better to get to the root of issues to obtain a clearer picture for subsequent corrective line of awareness-creation. This is because the residents had genuine issues that cried out for immediate attention. This notwithstanding, it was evident that almost all respondents were fully aware of how their attitudes to certain daily activities gave birth to the insanitary condition within their neighbourhood, and on their streets. They therefore acknowledged the need to team up for improving their existing conditions.

Residents demonstrated a high level of commitment to what they deemed to be a worthy cause by opening up to the team of researchers. These included suggesting pre-emptive measures to curtail insanitary practices; sharing insightful opinions for improving sanitation in the neighbourhood; buying into the concept behind the design intervention and attending meetings for discussions in line with the study. The study therefore had stimulated an atmosphere of team building for attaining a worthy cause. Through door-to-door interaction, tacit knowledge of the study was conveyed to the residents. In conjunction with stakeholders and other technocrats, a programme line-up was generated for the study.

\subsection{Results as Claims}

\subsubsection{Hopeful design intervention}

How do stakeholders perceive the conditions of their environment using participatory design-thinking approach?

- Residents have embraced the design thinking approach by responding to consistent and conscious efforts to sustain clean status of their streets for the related premium of being tagged as the cleanest street in the community. Indeed, five months after take off, there were clear indication that residents uphold clean sanitation conditions since they were using every available means to ward off residents who create the unsanitary conditions 


\subsubsection{Voice of end-users}

What are the benefits of including stakeholder voices in decision-making in sanitation planning for the earmarked streets?

The inclusion of the stakeholders' voices in decision-making as far as sanitation planning on the earmarked streets were concern, boosted the self-efficacy of the residents. They identified themselves as key figures ensuring the proper sanitation on the streets and beyond. Besides, residents were able to pinpoint certain insanitary practices and acknowledged the need to improve their attitude to environmental sanitation. The end-user voices were the catalysts that encouraged contributions by the stakeholders - landlords, tenants, and residents - that sought to work toward improved sanitation and environmental sustainability. The residents had wilfully demonstrated plans to team up with each other and with collective effort had a practical impact on reducing insanitary practices.

The findings of the study primarily sprang from the flexibility of the use of integrated methodologies with the aforementioned research tools. These tools were deployed to identify the basic difficulties among residents from the two streets preventing them from developing a sustainable environmental sanitation programme:

- $\quad$ seek for voices on how sanitation problems could be addressed and how measures could be put in place to attain sustainable environmental sanitation

- identify what they considered to be their role or contribution to achieving sustainable clean environment on their streets which with time could hopefully change attitude towards sanitation.

Interactions with residents encouraged them to be more sensitive to environmental sanitation in their own neighbourhoods. Residents discussed the root causes of the insanitary conditions in their community and chose cooperative or participatory ways to solve their problems. The findings of the study hinged on six hypothetical themes emanating from an open-ended interviews with residents (on the two streets) that were recorded, transcribed and coded. These were namely:

\section{a. Attitudinal challenges \\ b. Physical situation of environment \\ c. Voices in co-design \\ d. Co-creation and co-design}

The aforesaid themes were useful and helpful to the panel of judges. This is because, transcripts of interviews from which the themes were generated were not only used to identify difficulties experienced by the residents, but were also used for creating criteria for awarding marks to the two contending streets vying for recognition as the cleanest street in the community.

With regard to attitudinal challenges, indiscriminate disposal of domestic waste and human excreta were proven to be the principal cause of diseases and floods in the community. One attitudinal issue emanating from dialogue with the residents had to do with misleading notion that rainwater was a flawless means to carry away waste; another mistaken notion was that the streets are for the government and must be kept clean by the government workers.

The study also revealed that, residents had critical knowledge about the physical situation of the environment in that the inconvenient placement of the refuse dump far from the vicinity discouraged the proper disposal of wastes. As lamented by the residents, the streets were also observed to have too many improvised open gutters on them and needed well-constructed drains instead. In accordance with the concern raised repetitively, houses were found without constructed drains from their bathrooms; there were no drains by the sides of street; and improvise potholed drains on the street which mostly leave liquid waste stagnant. Besides, the physical conditions of the roads were a threat to the comfort and health residents. This was especially so for those living by the roadside that complained that the dust deprived them of physical neatness, and even access to transportation when it rained.

As part of exploring voices in co-design in decision-making, probing discourse brought to light that educating resident to adopt proper attitudes to sanitation and sanctioning miscreants guilty of insanitary would be helpful. Interaction with residents also revealed other prospects among them forming clubs to bring residents under one umbrella to improve sanitation; next, residents considered the construction or improvement of roads and the placement of litterbins at vantage points. Additionally, residents proposed allowing members of the community to dispose of waste free of charge. It also emerged that illicit structures by the roadside, had to be pulled down. Dialogues with stakeholders - landlords, tenants, and residents - employing co-creation and co-design for proper 
sanitation, produced useful suggestions.

\subsection{Social Innovation produce social healing}

Significantly, two antagonistic factions in the community used the co-designing stage to iron out their differences and eventually played major roles in supervising and adjudicating the development process. This ethnographic study produced "social healing" and community building. The participatory approach of the design intervention eventually got not only the two ruling frontrunners together but also their followers. Prior to the study, there had been simmering unhealthy relationship between two classes of people in the community. In discussions with some opinion leaders, it was realized that these simmering tensions somehow has craved into the issue of some of the insanitary conditions. This unhealthy gap between the two ruling classes in the community caused by factionalism was bridged owing to the merging nature of the study. Thus, the participatory approach encouraged bonding among the stakeholders (including the respondents), and especially between the superiors of the community such as the assemblyman and the chief, who until the initiation of this research were embroiled in rifts. IDEO (2015) divulges that social innovation shapes rising transformation (including attitudes) in underprivileged or deprived societies. Hence, design-thinking using a social innovation paid off, especially as it united co-researchers or end-users to heartedly share responsibilities.

On the use of FraIM as methodological route, it allowed for flexibility and proved to be resourceful. Engaging in co-designing and co-creation, especially with non-designers, meant one needed to be empathetic in their approach. Integrated methodologies meant that, the researchers were not only mindful of their participants, but also their ability to flow in the study without being seen to be pressurised.

\section{Conclusion}

The study has established that poor environmental sanitation in the Zongo communities retard the development of the country (Odunuga 2010). One basic cause is poor attitude to cleanliness that leads to poor health, floods, loss of lives and destruction of properties. Regrettably, inadequate efforts to address the situation have, alongside other reasons, led Ghana to the embarrassing rank of the 7th Dirtiest Country in the world. The ever-increasing poor environmental sanitation particularly in the Zongo communities has resulted in tarnishing the image of the country, deterring foreign investors from considering Ghana as an investment destination (Owusu 2010). The goal of this study was to test a design approach to stimulate and support sustainable environmental sanitation in Moshie Zongo, a Muslim community in Kumasi. It also sought to discover the opinions, awareness, attitudes and practices towards sanitation by selected residents of the Moshe Zongo community.

In accordance with the voices in co-design from the community, the study recommends that inclusion of the stakeholders' voices in decision-making on sanitation planning principally advance self-worth among residents as they felt playing pivotal role as far as the study was concerned. Residents (landlords and tenants) must therefore be involved in decision-making on sanitation planning. The study adopted a bottom-up approach, using Design for Social Innovation whereby co-creation and/or co-designing is employed with the main stakeholders; residents, landlords and designers in prototyping a design system for tackling sanitation and environmental issues within a section of the community. The design intervention ("5-Star Street Project") that entices residents to fulfil sanitation and environmental instructions should be fortified by opinion leaders for some time, to embed the participatory approach in tackling sanitation problems.

\section{References}

Adubofour, K, K Obiri-Danso, and C Quansah. 2013. "Sanitation Survey of Two Urban Slum Muslim Communities in the Kumasi Metropolis, Ghana." Environment and Urbanization 25 (1): 189-207. https://doi.org/10.1177/0956247812468255.

Alexander, Prince Willem. 2008. “Sanitation : A Human Rights Imperative.” Water, 50.

Asante, Abednego Asiedu. 2012. "No TitleGhana Recorded 9,542 Cholera Cases with 100 Deaths in 2012 Minister.”

Atkin, Charles. 2001. "The Integrated Behavioural Model for Water, Sanitation, and Hygiene: A Systematic Review of Behavioural Models and a Framework for Designing and Evaluating Behaviour Change Interventions in Infrastructure-Restricted Settings."

Brewer, J. D. (2000). Ethnography. Buckingham: Biddles Limited, Guildford and Kings Lynn. 
Conant, J. (2005). Sanitation and Cleanliness for a Healthy Environment, 52. Retrieved from http:ororwww.unwater.orgordownloadsorEHB_Sanitation_EN_lowres.pdf

Cruickshank, L; Coupe, G; Hennessy, D. 2013. "Co-Design: Fundamental Issues and Guidelines for Designers: Beyond the Castle Case Study." Swedish Design Research Journal 2 (13): 1-10. https://doi.org/10.3384/svid.2000-964X.13248.

Dalsgaard, P., 2012. Participatory Design in Large-Scale Public Projects: Challenges and Opportunities. Design Issues, 28(3), pp.34-47. Available at: http://www.mitpressjournals.org/doi/abs/10.1162/DESI_a 00160.

Dreibelbis, Robert, Peter J Winch, Elli Leontsini, Kristyna R S Hulland, Pavani K Ram, Leanne Unicomb, and Stephen P Luby. 2013. "The Integrated Behavioural Model for Water, Sanitation, and Hygiene: A Systematic Review of Behavioural Models and a Framework for Designing and Evaluating Behaviour Change Interventions in Infrastructure-Restricted Settings.” BMC Public Health 13 (1): 1015. https://doi.org/10.1186/1471-2458-13-1015.

Hunn, Amanda, Nick Fox, and Amanda Hunn. 1998. “Trent Focus for Research and Development in Primary Health Care Using Interviews in a Research Project."

IDEO. (2015). Social Innovation. Retrieved from http:ororwww.ideo.comorexpertiseorsocial-innovationor

Jenkins, M. (1998). THE FOCUS GROUP, A QUALITATIVE RESEARCH METHOD Reviewing The theory , and Providing Guidelines to Its Planning, (10298), 1-22. Retrieved from https:ororwww.google.com.ghorsearch?q=what + is + focus + group + discussion\&ie=utf-8\&oe=utf$8 \&$ client $=$ firefox-bab\&gfe_rd=cr\&ei=6GuxWKPfJKT98wfcjYHQCQ\#q=what+is+focus+group+discussion+pdf\&*

Lau, Jonathan. 2011. "Designing Sanitation Projects in Rural Ghana."

Lee, Y.S., 2014. Sustainable Design Re-examined : Integrated Approach to Knowledge Creation for Sustainable Interior Design. International Journal of Art and Design Education, 33(1), pp.157-174.

Manzini, Ezio. 2015. “Design, in a Connected World.” In Design, When Everybody Designs, First, 01:1-19. MIT Press.

Odunuga, Kehinde. 2010. “Analysis Of Domestic Water Use For Commercial Activities Among The Poor In Alajo And Sabon Zongo Communities Of Accra, Ghana.” UNIVERSITY OF MANITOBA.

Owusu, G. 2010. "Social Effects of Poor Sanitation and Waste Management on Poor Urban Communities: A Neighborhood-specific Study of Sabon Zongo, Accra." Journal of Urbanism: International Research on Placemaking and Urban Sustainability Vol 3 (2): 145-60. https://doi.org/DOI: 10.1080/17549175.2010.502001.

Plowright, David. 2011. Using Mixed Methods: Framework for an Integrated Methodology. 1st Editio. London: Sage Publications.

Saywell, Darren, and Caroline Hunt. 1999. "Sanitation Programmes Revisited Task No : 161.” Technology.

Sullivan, Graeme. 2009. "Making Space: The Purpose and Place of Practice-Led Research.” In Methodologies of Practice-Led Research and Research-Led Practice, 39-65.

Szebeko, D., and L. Tan. 2010. "Co-Designing for Society.” Australasian Medical Journal 3 (9): 580-87. https://doi.org/10.4066/AMJ.2010.378.

Tashakkori, Abbas, and John W Creswell. 2007. "The New Era of Mixed Methods." Journal of Mixed Methods Research 1 (1): 3-7. https://doi.org/10.1177/2345678906293042.

Weinreich, Nedra Kline. 2011. "Influencing Behavior by Design." Hands-On Social Marketing: A Step-by-Step Guide to Designing Change for Good, 93-104.

Wijk, Christine Van, Tineke Murre, and Steven Esrey. 1995. "Motivating Better Hygiene Behaviour : Importance for Public Health Mechanisms of Change."

Wiles, Rose, and Graham Crow. 2013. What Is Qualitative Interviewing ? 'What Is ?'Research Methods Series Edited by Graham Crow, University of Edinburgh. 